\title{
EL DISEÑO CLÁSICO O ANGLOSAJÓN DE JUICIO POR JURADOS Y LA VIOLACIÓN DEL DEBER DE MOTIVAR: UN ANÁLISIS A PARTIR DE LAS SENTENCIAS DE LA CORTE INTER- AMERICANA DE DERECHOS HUMANOS Y LA CORTE SUPREMA DE JUSTICIA DE LA NACIÓN.
}

\author{
THE CLASSIC DESIGN OR ANGLO-SAXON TRIAL BY \\ JURIES AND THE VIOLATION OF THE DUTY TO \\ MOTIVATE: AN ANALYSIS BASED ON THE JUDGMENTS \\ OF THE INTER-AMERICAN COURT OF HUMAN RIGHTS \\ AND THE SUPREME COURT OF JUSTICE OF THE NATION.
}

RESUMEN:

Se encuentra en marcha un fuerte movimiento de reforma procesal penal en la Argentina incorporando la participación ciudadana en la administración de justicia por medio de la institución de juicios por jurados. Numerosas provincias entre las que se cuentan Buenos Aires, Mendoza, Neuquén, Chaco, San Juan, Rio Negro, entre otras han incorporado ya el diseño de juicio por jurado clásico o anglosajón.

El presente trabajo analiza este movimiento de la reforma y los cuestionamientos a la constitucionalidad de la instauración del juicio por jurado clásico por implicar la introducción del veredicto inmotivado a través del análisis crítico de los recientes fallos de la Corte Interamericana de Derechos Humanos y la Corte Suprema de Justicia de la Nación que analizaron este problema constitucional y poniendo de manifiesto cuales los argumentos por las cuales estas decisiones son contradictorias con la práctica interpretativa de ambos tribunales que han consagrado un derecho autónomo a la motivación y a un sistema de revisión amplio de las sentencias, como garantías del debido proceso.

\section{ABSTRACT}

A strong criminal procedural reform movement is underway in Argentina, incorporating citizen participation in the administration of justice through the institution of jury trials. Numerous provinces among which are Buenos Aires, Mendoza, Neuquén, Chaco, San Juan, Rio Negro, among others, have already incorporated the design of trial by classical or Anglo-Saxon jury.

1 Abogado UNC. Magister en Derecho y Argumentación Jurídica UNC. Docente e investigador. carlosvillanueva2608@gmail.com. 
The present work analyzes this movement of the reform and the questions to the constitutionality of the establishment of the trial by classic jury for implying the introduction of the unmotivated verdict through the critical analysis of the recent decisions of the Inter-American Court of Human Rights and the Supreme Court of Justice of the Nation that analyzed this constitutional problem and showing that the arguments by which these decisions are contradictory with the interpretative practice of both courts that have enshrined an autonomous right to motivation and a system of comprehensive review of sentences, as guarantees of due process.

PALABRAS CLAVE: Juicio por Jurados - Reforma Procesal Penal - Constitución Nacional - Corte Interamericana de Derechos Humanos - Corte Suprema de Justicia de la Nación.

KEY WORDS: Trial by Juries - Criminal Procedure Reform - National Constitution - Inter-American Court of Human Rights - Supreme Court of Justice of the Nation.

\section{Introducción.}

El diseño de juicio por jurados clásico se encuentra vinculado a la elección de un sistema en el cual la exigencia de racionalidad de la decisión se agota en que la resolución se encuentre basada en razones sin que abarque la exigencia de que las mismas se encuentren expresadas. Esto parece ir en contra del paradigma de la motivación de la cultura jurídica continental que ha incrementado la exigencia de racionalidad en la aplicación del derecho. En ese sentido, la tendencia a la incorporación de la motivación como deber fundamental de los jueces y como derecho fundamental de los ciudadanos se ha profundizado, primero, con la incorporación dentro de las nuevas Constituciones latinoamericanas y europeas de una garantía específica de motivación dentro de las garantías de debido proceso y, en segundo lugar, por su reconocimiento en la jurisprudencia de los Tribunales de Derechos Humanos

La Corte Interamericana de Justicia en el año 2018 y la Corte Suprema en el presente año se han abocado a resolver casos en los cuales se encontraba en discusión la posible violación de garantías procesales del debido proceso por parte del diseño clásico de participación ciudadana en la justicia, el cual ha sido elegido en Latinoamérica y Argentina, como el modelo preponderante.

\section{El proceso de reforma procesal penal y participación ciudadana:}

Luego de casi un siglo y medio de silencio legislativo respecto a la incorporación de juicio por jurados para el juzgamiento de causas penales como estaba previsto en los artículos 24, 75 e inciso 22 y 118 de la Constitución nacional, se dio a partir de los años noventa un creciente movimiento de reforma procesal penal en las Provincias Argentinas con el eje puesto en la participación ciudadana en su juzgamiento. Este proceso de reforma tiene dos momentos muy claros y diferenciados. El primer momento, tuvo a la Provincia de Córdoba como protagonista siendo la primera provincia del país en incorporar el juicio por jurado para el juzgamiento de causas criminales. El proceso de incorporación de los juicios por jurados tiene como antecedente inmediato en la provincia de Córdoba el artículo 162 de la Constitución de la Provincia de Córdoba, sancionada en 1987, que habilito que por medio de una ley se pudiera determinar en que casos los 
tribunales estarían integrados por jurados. En el año 1992 se sancionó la reforma del Código Procesal Penal de la Provincia de Córdoba. En esta reforma integral del Código se incorporó el juicio por jurado escabinado. A partir de su implementación en el año 1998 comenzó a regir en el sistema de justicia de la Provincia de Córdoba.

El sistema adoptado por esta ley era el escabinado, que se está compuesto por dos legos junto a tres jueces profesionales y se implementa en aquellos delitos cuyo máximo de la escala penal prevista para el o los delitos contenidos en la acusación fuere de quince años de pena privativa de libertad o superior, siempre a pedido de parte, ya sea el imputado, el querellante particular o el fiscal de la causa. Los jurados legos, en este sistema, tienen en este sistema las mismas atribuciones que los jurados técnicos y resuelven las cuestiones de hecho y de derecho motivando su decisión. Este diseño de participación ciudadana fue elegido justamente porque permitía salvaguardar la exigencia constitucional de motivación de las sentencias incorporada en el artículo 155 de la Constitución Provincial.

En el año 2004, como consecuencia de los reclamos de mayor seguridad de la ciudadanía vinculadas al caso "Blumberg", se impulsó desde el poder ejecutivo la sanción de la Ley 9182, aprobada el 22 de setiembre de 2004 por la legislatura cordobesa. Esta ley estableció un juicio por jurados con participación ciudadana mayoritaria en el juzgamiento de acusados que hayan cometido delitos de corrupción administrativa y otros graves delitos en contra de las personas. En esta oportunidad el proyecto originariamente impulsado establecía el juicio por jurado anglosajón pero las oposiciones en el trámite parlamentario en base a que este diseño violaba la exigencia del artículo 155, derivo en que el proyecto fuera modificado y se introdujera un diseño original, con participación de mayoría de legos, pero con motivación de la sentencia a cargo de los jueces técnicos. El segundo momento de reforma, comienza por el impulso de autores como Binder, Maier, Granillo y Harfush, entre otros quienes, desde instituciones como Asociación Argentina de Juicios por Jurados, el Instituto de Estudios Comparados en Ciencias Penales y Sociales (Inecip) comienzan a impulsar la incorporación del juicio por jurado anglosajón o clásico. La elección de este tipo de diseño de juzgamiento estaba basada en que el mismo representaba la forma más clara de introducir el procedimiento acusatorio, la oralidad, el principio de inmediación y mayores garantías para el imputado.

Este impulso tuvo su primera conquista con la promulgación en la Provincia de Buenos Aires de la ley 14.543, del año 2013, que establece que a pedido de parte podrá disponerse la integración por jurados con un diseño clásico. El jurado se encuentra compuesto por doce miembros legos titulares y seis suplentes, y un juez técnico que actúa como director del proceso pero que no interviene en el veredicto. El veredicto de culpabilidad o inocencia al cual el jurado arriba luego de un proceso de deliberación conjunta, es inmotivado, es decir, que no se van a expresar las razones por las cuales se arribó a esa decisión. Otro elemento a destacar es que la sentencia es irrecurrible en caso de la absolución del imputado.

Luego de la sanción de esta norma, se intensifico este segundo momento del movimiento de reforma procesal, con la incorporación del mismo modelo en las provincias de Neuquén, Mendoza, Chaco, Rio Negro, San Juan y media sanción en la provincia de Santa Fe y se encuentra bajo estudio proyectos de reforma en la mayoría de las provincias argentinas. En el Congreso Nacional también se han presentado proyectos en tal sentido, siendo el proyecto de diputados de la UCR (Burgos, Vega) el último en tener tratamiento parlamentario. 


\section{La postura de la Corte Interamericana ante los planteos de inconvencionalidad por el veredicto inmotivado del jurado Clásico: caso "V.R.P., V.P.C. y otros vs. Nicaragua"}

Luego de años de expectativa jurídica dentro de la doctrina respecto a la posición que iba a tomar la Corte Interamericana de Derechos Humanos (Villanueva, 2015) respecto a la convencionalidad de los juicios por jurados de diseño clásico, duda principalmente focalizada en torno al debate sobre el veredicto inmotivado y su vulneración al derecho al recurso, finalmente el 8 de marzo de 2018 dicto sentencia en el caso "V.R.P., V.P.C. y otros vs. Nicaragua", en la cual se expidió por la viabilidad convencional de este tipo de mecanismos jurisdiccionales².

El caso tenía como plataforma fáctica un hecho de violencia sexual contra una menor de trece años de edad. La resolución término condenando a Nicaragua por considerar que dicho estado había violado la protección adecuada respecto a la víctima de esta clase de caso y la acusación había incurrido en la re-victimización de la misma. Asimismo, la Corte IDH señalo que Nicaragua no tenía una legislación procesal penal ni protocolos de actuación que permitiera evitar esta clase de procesos de re victimización en menores de 18 años, a través de regulaciones claras para los operadores del sistema judicial (jueces, fiscales, peritos interdisciplinarios). Para la Corte IDH, Nicaragua había afectado en el caso, la dignidad, la reserva, la intimidad y vulnerabilidad de la víctima y su madre. Sin duda, este fallo constituye un importante precedente sobre el juzgamiento con perspectiva de género de esta clase de delitos y merece un oportuno tratamiento. Sin embargo, el punto que nos interesa profundizar en el presente trabajo, son las consideraciones realizadas sobre el procedimiento de juicio por jurados del Estado de Nicaragua. Los considerandos más importantes en este sentido se encuentran a partir del considerando 204 de dicha resolución. La primera tesis de la Corte es que las garantías constitucionales en la Convención Americana son aplicables al sistema de Juicio por jurados y recurre a la idea de que en su redacción sus autores no tenían en mente un sistema penal específico y remitiéndose al antecedente del Caso Fermín Ramírez ${ }^{3}$. La Corte utilizando un argumento de autoridad afirma que esta es la posición asumida por la Corte Europea de Derecho de Derechos Humanos (CEDH) en el juicio de Taxquet contra Bélgica, al cual nos referiremos más adelante. ${ }^{4}$

Afirma que el juicio por jurado no es en sí mismo incompatible con el sistema de garantías sino que ello debe analizarse en su diseño concreto, y resaltando su importancia señala que su finalidad como modelo está vinculado con la idea de la legitimación del sistema judicial, una forma de democratización y un acercamiento de la impartición de justicia a la sociedad, siendo utilizado el juicio por jurado un modelo utilizado en 21 de los 35 miembros de la OEA, siendo el diseño más utilizado el clásico o anglosajón.

Los diversos diseños de juicio por jurados adoptan diversos sistemas de valoración de la prueba y según la Corte esto afecta la exigencia de exigencia de motivación o la forma de exteriorización de fundamentación. Referido al juicio por jurados clásico, este

\footnotetext{
2 El fallo lleva la firma de los jueces Eduardo Ferrer Mac-Gregor Poisot, Humberto Antonio Sierra Porto,Elizabeth Odio Benito, L. Patricio Pazmiño Freire y Eugenio Zaffaroni. Extrañamente este juez había sido un exponente principal en contra del juicio por jurado anglosajón, posición que quedo asentada en el obiter dicta del fallo "Casal".

3 Caso Fermín Ramírez Vs. Guatemala. Fondo, Reparaciones y Costas. Sentencia de 20 de junio de 2005. Serie C No. 126, párr. 66. Se resalta que "[1] a Convención no acoge un sistema procesal penal en particular. Deja a los Estados en libertad para determinar el que consideren preferible, siempre que respeten las garantías establecidas en la propia Convención, en el derecho interno, en otros tratados internacionales aplicables, en las normas consuetudinarias y en las disposiciones imperativas de derecho internacional".

4 TEDH, Caso Taxquet Vs. Bélgica [GS], No. 926/05. Sentencia de 16 de noviembre de 2010, párr. 83. En realidad es un mal argumento de autoridad para el diseño clásico de juicio por jurados ya que lo que se estaba analizando era el modelo de jurado que tiene un cuestionario de preguntas dirigidas a los legos sobre los hechos y sobre los cuales se construye la resolución por lo que no es el modelo seguido ni en Nicaragua ni en nuestro país.
} 
opta históricamente por un veredicto de legos que no se prescribe una motivación o exteriorización de la fundamentación y el fundamento es que este sistema se basa en la es sistema de valoración de la prueba de la íntima convicción de los jurados legos. (considerando 224).

Este diseño, prima facie, parece incompatible con lo que la Corte misma señala en su considerando 254 respecto al deber de motivación que la Corte señala como una de las garantías básicas del debido proceso incluidas en el 8.1 de la Convención Americana de Derechos Humanos y a la que caracteriza como la exteriorización de la justificación razonada que permite llegar a una conclusión. Recurriendo a su análisis del concepto en su precedente Apitz Barbera, la Corte señala que la misma implica una exposición racional de las razones que llevan al juzgador a adoptar una decisión. Profundizaremos en esta concepción cuando realicemos el análisis conceptual de lo que implica y que fundamentos tiene la motivación de la sentencia.

Sin embargo, la Corte considera que pese a esta caracterización el diseño clásico o anglosajón en sí mismo no vulnera este deber de motivación. Establece es su considerando 259 y 260 que "La Corte estima, como lo ha hecho el Tribunal Europeo de Derechos Humanos, que la falta de exteriorización de la fundamentación del veredicto no vulnera en sí misma la garantía de la motivación." Además de este argumento de autoridad, señala en un párrafo que merece especial análisis que "En efecto, todo veredicto siempre tiene motivación, aunque como corresponde a la esencia del jurado, no se expresa". Pero establece una condición para tal aceptación y es que el veredicto pueda permitir que, en base a las pruebas y debate de la audiencia, quien lo valore puede reconstruir el curso lógico de la decisión de la decisión de los jurados "quienes habrían incurrido en arbitrariedad en el supuesto en que esta reconstrucción no fuera viable conforme a pautas racionales."

Para la Corte IDH, el principio de interdicción de la arbitrariedad de la decisión puede garantizarse en los sistemas que tienen juicios por jurados, con veredicto inmotivado, con otras garantías procesales: instrucciones previas ${ }^{5}$, cuestionarios de preguntas a responder por los jurados por escrito y que se acompañan al expediente 6 , anulación del proceso cuando el veredicto de culpabilidad sea contrario manifiestamente a la prueba rendida en el proceso ${ }^{7}$, recusación con y sin expresión de causa ${ }^{8}$, audiencia de Voir para detectar sesgos o circunstancias que afecten la imparcialidad de los jueces legos ${ }^{9}$, facultad de indagar a los jurados sobre la existencia especifica de unanimidad ${ }^{10}$ y curso $^{\circ}$ de capacitación para ciudadanos con el objeto de promover el conocimiento para el cumplimiento de su tarea".

Para la CIDH, el diseño clásico, con su veredicto inmotivado no violara las garantías de debido proceso si logra mostrar que el procedimiento penal estatal ofreció mecanismos de salvaguardia contra la arbitrariedad y que permitieran comprender las razones del veredicto tanto al acusado, a la víctima como a la parte acusadora.

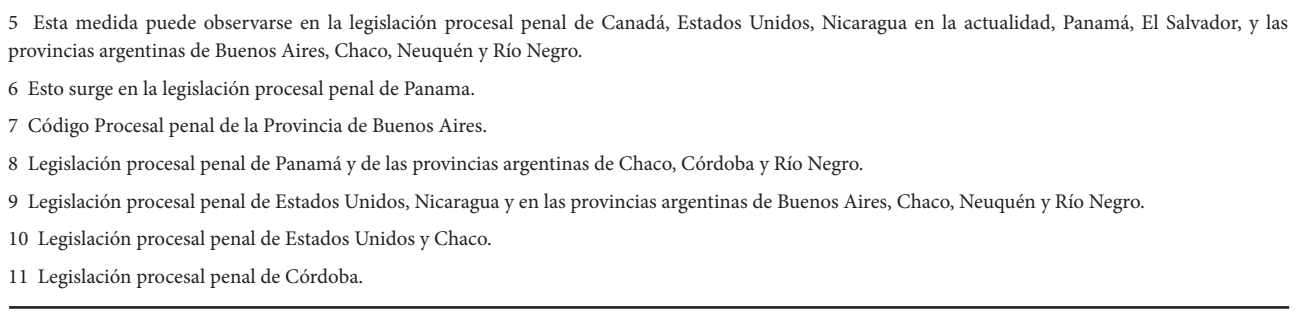




\section{La posición de la Corte Suprema de Justicia de la Nación}

"Recurso de hecho deducido por la defensa de Alex Mauricio Obreque Varas y Alexis Gabriel Castillo en la causa Canales, Mariano Eduardo y otro s/ homicidio agravado impugnación extraordinaria"

La Corte Suprema de la Nación recientemente con fecha 2 de mayo de 2019, con una decisión histórica y controversial sentencia ha tomado una posición respecto a la constitucionalidad del juicio por jurado clásico y el cuestionamiento al veredicto inmotivado. La CSJN analiza una causa en la cual recayó un veredicto inmotivado que decidió la culpabilidad de los imputados Alex Mauricio Obreque Varas y Alexis Gabriel Castillo, quienes habían sido acusados como coautores de un homicidio agravado de Edgardo Daniel Arias. El homicidio era agravado por haber realizado por alevosía, premeditación de dos o más personas y por arma de fuego. En primera instancia, los imputados habían sido condenados a la pena de prisión perpetua más inhabilitación. La sentencia fue recurrida por los condenados frente al tribunal de impugnaciones y el Tribunal Superior de Justicia de la Provincia de Neuquén, siendo confirmada la misma en ambos casos. Con posterioridad, los condenados interponen Recurso Extraordinario Federal ante la Corte Suprema de la Nación Argentina.

La Corte resuelve por mayoría el fallo, con voto particular de Rosatti, y el juez Carlos Rosenkrantz, en disidencia, quien desestimó la queja in limine. La mayoría del Tribunal, compuesta por Lorenzetti, Maqueda y Rossati, se avoco al tratamiento del recurso y decidió, que dentro de las agravios invocados, los vinculados a la constitucionalidad de la ley la ley $n^{\circ} 2784$ de la provincia de Neuquén que instauro el juicio por jurados correspondía a la materia federal y por lo tanto debían ser dirimidos por la Corte.

Los recurrentes en sus agravios atacan la constitucionalidad de la norma que regula la incorporación del juicio por jurado Neuquino en razón de que: 1) La instauración del juicio por jurados por la provincia de Neuquén no era una facultad de las provincias sino de la nación según la interpretación literal del artículo 24 e inciso 75 inciso 12, siendo una atribución federal y no local. 2) La obligatoriedad del juicio por jurados contemplada en el artículo 35 de la ley provincial 2784 para cierta clase de delitos graves violaba el artículo 24 de la Constitución Nacional del cual se desprende que el mismo debe ser considerado como una garantía del imputado y por tanto debe ser renunciable por su parte. 3) Las mayorías exigidas por la ley para el juicio por jurado Neuquino que exige las dos terceras partes de los votos (ocho votos sobre doce) viola el principio de inocencia, ya que el principio de fallar más allá de toda duda razonable exige la unanimidad atenta que el veredicto de este diseño clásico no exige motivación del veredicto. Asimismo, adujo que la norma violaba la igualdad ante la ley al existir provincias que habían incorporado el criterio de unanimidad como regla de mayoría requerida para la condena. 4) La aplicación de este diseño de juzgamiento establecido por ley con fecha posterior al hecho del proceso vulneraba el principio de juez natural.

En el presente trabajo solo analizaremos la tercera línea de agravio, pero no podemos dejar de manifestar nuestra conformidad respecto a lo establecido por la Corte Suprema respecto a la facultad de las provincias de instaurar el juicio por jurado en su territorio, siendo una facultad no delegada y que una interpretación sistemática y evolutiva de la Constitución Nacional determina que la ley nacional que instaure el juicio por jurados solo puede tener el alcance de la competencia federal.

Asimismo, que el juicio por jurados sea obligatorio o facultativo es una potestad también provincial. La discusión acerca del alcance del artículo 24 de la CN solo compromete a la eventual ley de juicio por jurados que se dicte para todo el territorio nacional 
en el marco de la competencia federal. Las distintas provincias han adoptado uno u otro sistema, por ejemplo, el Código Procesal Penal de la Provincia de Buenos Aires opta por un sistema facultativo mientras que Córdoba y Neuquén un sistema obligatorio.

Sobre el tercer punto de agravio, puede apreciarse que la mismo posee dos partes, por una parte, fundamental que un sistema de mayorías no es constitucional en el caso del juicio por jurados por ser depender de un veredicto inmotivado y por otra parte por ser contrario al principio de igualdad al existir provincias en los cuales se exige la unanimidad. Varias consideraciones se pueden realizar antes de entrar al análisis del punto que nos interesa en este trabajo. Comenzando por el argumento más débil del agravio referido al principio de igualdad se puede observar que en el derecho comparado, interno como internacional, existe una gran diversidad de sistemas respecto a las mayorías exigidas en el veredicto, en algunos Códigos se exige la Unanimidad y en otros casos la mayoría agravada ${ }^{12}$, sin que esa diferencia de posturas regulativas impliquen una violación del principio de igualdad. La discusión más interesante sobre el tópico de las mayorías en el veredicto, se encuentra en analizar si el estándar probatorio de condenar "más allá de toda razonable" como derivado del principio de inocencia, excluye la posibilidad de que existan disidencias en el jurado pues, per se, representarían la existencia de una duda razonable. Este argumento no esgrimido por la parte merece atención. Si uno o varios miembros que son minorías en un tribunal han llegado a una convicción de inocencia fundados en razones en una deliberación de jurados deben ser tomados como una duda razonable. Sin embargo, estos argumentos, como hemos adelantado, no fueron desarrollados en el recurso de la parte ni en la resolución de la Corte y si lo fue la vinculación entre las mayorías y la inexistencia de la motivación.

La Corte Suprema se avoco a tratar, a nuestro modo de ver Obiter dicta, sobre la constitucionalidad del juicio por jurados clásico en función de la ausencia de motivación. La primera afirmación que realiza la Corte es que la vinculación pretendida entre la mayoría exigidas y el carácter de inmotivado del veredicto del jurado, no se da en el juicio por jurados clásico en tanto y en cuento está garantizado el derecho al recurso. Para la Corte el carácter inmotivado de los veredictos no impone la inexorable exigencia legal de unanimidad, ya que esta "la falta de motivación expresa de estos veredictos no ha impedido el ejercicio efectivo del derecho a la revisión amplia de las decisiones judiciales, a punto tal que los recurrentes no han formulado agravio a este último respecto." Como demostraremos, la Corte intentará a partir de este punto justificar el veredicto inmotivado y la forma en que esto no afecta garantías constitucionales, a nuestro modo de ver a través de una argumentación incorrecta y confusa desde el punto de vista conceptual, sino que asimismo no demuestra que el veredicto inmotivado no implique una restricción al derecho a una revisión amplia de la sentencia, aun cuando efectivamente el recurrente en este caso no lo haya tomado como punto de agravio.

¿Cómo argumenta la Corte que el veredicto inmotivado no afecta garantías del debido proceso? 1) Toma un punto de partida histórico y nos va a decir que "la exigencia de motivación de la sentencia de los jueces profesionales fue concebida originalmente como un modo de compensar la debilidad institucional y la falta de garantías políticas de estos magistrados respecto de los jurados populares.". Esta reconstrucción histórica es falsa para el sistema continental. En este sistema no se dio un paso de los jurados populares a los juzgados técnicos por el cual se justificaría la exigencia de motivación como fortalecimiento de la legitimidad del técnico frente al lego. En nuestro sistema continental la introducción de la motivación tiene que ver con la ruptura con el sistema

12 La provincia de Córdoba es una excepción ya que requiere solo la simple mayoría de quienes deben concurrir a dictar sentencia, contando los ocho legos y los dos técnicos con participación del presidente del tribunal en caso de empate. 
de justicia del antiguo régimen. En nuestro sistema la exigencia de motivación tiene su origen en la vinculación del juez a la ley, es decir, de la introducción y control del principio de legalidad en la jurisdicción como mecanismo de interdicción de la arbitrariedad. 2) La CS, por otro lado, intenta fortalecer este argumento y afirma que vinculado con este origen histórico la exigencia de la motivación, la expresión de razones explicitas encuentra su razón de ser en la obligación de rendir cuentas de sus decisiones frente a la ciudadanía por parte de estos jueces técnicos, representantes no electivos. La Corte realiza entonces, una distinción: Esta obligación de rendir cuenta es diferente cuando es la propia ciudadanía la que juzga, representado por alguno de sus miembros, y ejerce de manera directa esta potestad jurisdiccional, siempre que se el debido proceso y el ejercicio de defensa se encuentra garantizada por el juez profesional que preside el tribunal. Cuando debe dar fundamento de dicha diferencia recurre a un argumento de autoridad y remite al fallo de la Corte IDH "V.R.P., V.P.C. y otros vs. Nicaragua", que hemos descripto y rescata como puntos salientes "la motivación de las decisiones adoptadas por los órganos encargados de impartir justicia no es sólo relevante para el inculpado del delito, sino que permite también el control ciudadano de los actos de gobierno, en este caso de la administración de la justicia y los expone a su escrutinio. En el caso de los jurados, dicha vertiente se entiende cubierta en razón de la participación directa de la ciudadanía"

Este punto es controversial y tiene que ser vinculado con la teoría democrática que la sustenta: no resulta claro porque la decisión en su carácter de representantes de la ciudadanía los eximiría de responder frente al resto de los ciudadanos. En primer, lugar la idea de que se debe responder frente a la ciudadanía no depende de la elección por votación o sorteo, ni de su carácter permanente o transitorio. Si la idea de rendir cuenta solo dependiera del carácter no electivo del poder judicial entonces eximiría a los representantes de la ciudadanía seleccionado por vía electiva o por sorteo. Esta conclusión parece absurda. Todas las formas de representación de la ciudadanía en cuanto ejercen una función pública, ya sea está sea en carácter permanente o transitorio, deben rendir cuenta, incluso los jueces legos. Incluso si la posición de la Corte es afirmar que la rendición de cuenta existe pero es diferente, no es posible colegir de la sentencia ahora analizada cuál es ese modo de rendición de cuenta y tampoco queda claro la razón de porque debería excluirse este tipo de rendición de cuenta, si en definitiva, la forma más directa de poder establecer que una decisión no ha sido arbitraria es la explicitación de las razones que sustentaron esa decisión.

3) La Corte Suprema, se aboca a relacionar el modelo de la íntima convicción, el veredicto inmotivado y la ausencia de violación a la revisión de la sentencia. Describe la Corte que en el diseño de juicio por jurados clásico como el que tiene la provincia de Neuquén, los jurados legos luego de confrontar razones en deliberación conjunta, votan de acuerdo a su íntima convicción, por la culpabilidad o inocencia del imputado. Para la CSJN, el sistema de valoración de la prueba de "íntima convicción" no requiere expresión o explicación de los motivos que conformaron el convencimiento sobre la resolución adoptada para el caso, pero ello, no es violatorio de las garantías ya que no impide la adecuada revisión de lo decidido y la razón de ello es que:

La verdadera fundamentación no radica en la expresión escrita de razonamientos, sino en la coherencia entre las afirmaciones de las partes, las pruebas y el sentido de la sentencia. A este respecto, la Corte Interamericana ha precisado que entendía, tal "como lo ha hecho el Tribunal Europeo de Derechos Humanos ${ }^{13}$, que la falta de exteriorización de

13 Se refiere al fallo de la TEDH, Caso Taxquet Vs. Bélgica [GS], No. 926/05. Sentencia de 16 de noviembre de 2010, párr. 83. que como hemos dicho, se refiere a un tipo de jurado distinto ya que incluye preguntas a los legos con el cual se arma la motivación de la resolución. 
la fundamentación del veredicto no vulnera en sí misma la garantía de la motivación. En efecto, todo veredicto siempre tiene motivación, aunque como corresponde a la esencia del jurado, no se expresa. Pero el veredicto debe permitir que, a la luz de las pruebas y el debate en la audiencia, quien lo valora pueda reconstruir el curso lógico de la decisión de los jurados, quienes habrían incurrido en arbitrariedad en el supuesto en que esta reconstrucción no fuera viable conforme a pautas racionales

En el párrafo transcripto y los precedentes, surge que la Corte considera que la función de la motivación se agota en la revisión de la decisión y que por lo tanto no hay un deber autónomo de motivación que sea necesario satisfacer. Mientras sea posible comprobar por el órgano de control de la existencia de arbitrariedad en la decisión del jurado, en que el proceso de decisión puede ser reconstruible bajo pautas racionales es suficiente para que el veredicto inmotivado no pueda ser atacado como violatorio del derecho. Estos puntos serán analizados más adelante.

Es importante destacar que la Corte, considera que los procesos llevados a cabo para tomar la decisión cuando hay jurados legos no son diferente a los realizados por el juez técnico. La reconstrucción de un hecho de pasado, sea lego o técnico, es la misma. Tomando lo manifestado a su vez en el precedente de la Corte Interamericana, toda persona que se enfrenta a la tarea de reconstruir un hecho del pasado unas un método histórico. ¿En qué consistiría el método histórico que utilizamos? El método consistiría en una serie de pasos sucesivos para llegar a una definición sobre el hecho:

El primer paso consiste en delimitar las pruebas que tendrá en cuenta (Heurística).

El segundo paso consiste en valorar la prueba para determinar si las mismas no son materialmente falsas (Critica Externa).

El tercer paso es valorar la verosimilitud del contenido del material probatorio (critica externa).

El cuarto paso consiste en llegar a una síntesis, que implica la reconstrucción del hecho probado que da lugar a la decisión.

Para la Corte, el tribunal que revise la sentencia de primera instancia y cualquiera que quiera valorar el veredicto de primera instancia, debe reconstruir ese camino. Solo ese camino parece ser capaz de poder reconstruir la justificación de la decisión. La Corte presupone que se puede realizar esta reconstrucción, afirma "De modo que, pese a la ausencia de fundamentación escrita, es perfectamente posible cuestionar una resolución de un jurado en base a la incongruencia entre precedentes o premisas (afirmaciones y pruebas) y conclusión (culpabilidad o inocencia)."14

\section{Nuestra posición:}

Nuestra posición con respecto a estos dos fallos comentados es que la solución brindada en ambos en cuanto a que el juicio por jurados clásico no vulnera la garantía de motivación de las sentencias es incorrecta y las líneas argumentales utilizadas son contradictorias con las posiciones sustentadas con anterioridad por ambos tribunales que establecieron la existencia de un derecho autónomo de motivación y que de aplicar estos criterios debió declarase la inconvencionalidad de las leyes que instauran el juicio por jurado clásico.

14 La CS realiza un análisis final de la institución del juicio por jurados afirmando que la misma es una alternativa que permite conjugar la 'precisión' propia el saber técnico con la 'apreciación' propia del saber popular, congregando la garantía inherente al debido proceso y la percepción de la realidad propia de una decisión basada en el sentido común. Asimismo, para la CS, el ejercicio deliberativo previo a la toma de decisiones relevantes -como el veredicto de un jurado popular posee un efecto positivo para todos los participantes. Y citando a Nino, establece el 'valor epistemológico' de la construcción de consensos que implica la deliberación del jurado lego. (NINO, Carlos Santiago, "La paradoja de la irrelevancia moral del gobierno y el valor epistemológico de la democracia", en W.AA. "En torno a la democracia", Ed. Rubinzal - Culzoni, Santa Fe, 1990, pág. 97 y sgtes.). 
a- El necesario análisis conceptual sobre los términos: Fundamentar, justificar y motivar: Uno de los principales problemas que presenta la posición de la Corte IDH y por derivación la posición de la CSJN en cuanto utiliza su precedente, es que utiliza los términos de manera confusa y hasta contradictoria. Así claramente la Corte define a la motivación como exteriorización de razones, luego afirma que el juicio por jurados clásico, que no prescribe una motivación o exteriorización de la fundamentación y el fundamento es que este sistema se basa en la es sistema de valoración de la prueba de la íntima convicción de los jurados legos (224), para luego afirmar que la falta de exteriorización de la fundamentación del veredicto no vulnera en sí misma la garantía de la motivación (259) y lo más grave aún afirmar que todo veredicto siempre tiene motivación, aunque como corresponde a la esencia del jurado, no se expresa. (260).

Aquí parte de la confusión es la utilización indistinta de conceptos diversos como fundamentar, justificar y motivar y sus derivados.

Como hemos manifestado en otras oportunidades (Villanueva 2015, 2017) el término "fundamentar", presenta una estrecha relación con una red conceptual de otros términos similares como son los términos "justificación" y "motivación". Sin embargo, que la mayoría de las veces se toman como sinónimos, hay ciertas distinciones necesarias que hay que realizar: el término "fundamentación" tiene un primer tipo de ambigüedad semántica, como actividad y como producto de la actividad. Asimismo, posee otro tipo de "fundamentación" en un sentido amplio, que algo tenga fundamentación implica la idea de que la resolución tiene razones que lo sustenten, ya sea que estén expresadas o no estas razones. En un sentido más restringido, se afirma que algo está fundamentado cuando se expresan las razones que lo sustentan. En este segundo sentido es que la fundamentación coincide con el término motivación. También señalamos en esos trabajos que, en el sentido más amplio, la fundamentación jurídica implica la realización de un silogismo jurídico, basada en razones legales y fácticas. Así afirma Malem Seña:

Justificar o fundar una sentencia en derecho y en los hechos es construir un razonamiento válido donde una premisa hace referencia a una norma jurídica general, otra a consideraciones empíricas que deben aparecer suficientemente acreditados en los hechos probados y donde la conclusión es la decisión o el fallo (Malen Seña, 2008, pág. 24).

La misma concepción deductivista de la fundamentación normativa es sostenida por Bulygin quien expresa:

Justificar o fundar una decisión consiste en inferir una inferencia o razonamiento lógicamente valido, entre cuyas premisas figura una norma general y cuya conclusión es la decisión. Una decisión fundada es aquella que se deduce lógicamente de una norma general (en conjunción con otras proposiciones fácticas y a su vez, analítica). La decisión judicial no solo debe ser fundada, sino, además, debe ser fundada en normas jurídicas y en las circunstancias del caso. Esto significa que las normas generales que constituyen el fundamento normativo de la decisión deben ser-al menos en principio-normas jurídicas, y las proposiciones empíricas que integran los considerandos de la sentencia deben corresponder a las circunstancias del caso debidamente probados en autos (Bulygin 1991, pág. 356).

De las definiciones de justificación o fundamentación normativa antes reseñadas se pueden realizar algunas distinciones relevantes: la distinción entre la premisa normativa y la premisa fáctica, y por otro costado entre la distinción entre justificación interna y justificación externa.

La corrección lógica de la derivación constituye la justificación interna de la misma. La corrección y la validez de los razonamientos realizados por el juzgador, los cuales consisten, entre otras, en el cumplimiento de las exigencias de coherencia, no contradicción, 
tercero excluido, identidad y razón suficiente.

Para el cumplimiento de la exigencia de validez de la misma justificación dentro de esta concepción, no basta con el proceso de expresar las premisas del juicio, las circunstancias de hecho verificadas y las reglas jurídicas aplicables, sino la exposición de las razones de hecho y de derecho que justifican la decisión, es decir la exteriorización del porqué de las conclusiones-premisas de hecho y de derecho que el tribunal afirma, para arribar a la solución del caso. Siendo necesario en cuanto a la reconstrucción histórica de los hechos, exponer su relación con los elementos de prueba, válidamente incorporados al proceso y aptos para ser valorados a través de los cuales se arriba a una determinada conclusión fáctica. Valoración que debe ser cumplir con exigencias lógicas y de la experiencia y psicología común (Maier, 1989).

Esta exigencia de justificar, a su vez las premisas que integran el silogismo se conoce como justificación externa. Para los autores que sostienen la importancia de la distinción entre ambos tipos de justificación, afirmar que una decisión judicial se encuentra justificada jurídicamente si y solo si está justificada interna y externamente (Moreso, 2004; Gascón Abellán, 2004).

En el segundo sentido más estricto, la fundamentación implica motivación. La motivación constituye el aspecto expresivo de la fundamentación. Motivar es exponer, entonces, los argumentos fácticos y jurídicos que justifican la resolución. A través de la motivación de la sentencia se hace pública la reconstrucción racional de los razonamientos de hecho y de derecho en los cuales quien ejerce la función jurisdiccional basa su decisión.

Asimismo, este concepto de fundamentación como motivación, es el mismo que es utilizado por las modernas Constituciones europeas y latinoamericanas, y las prácticas interpretativas de los Tribunales Internacionales de Derechos Humanos, incluida la propia Corte IDH, cuando define la motivación y el contenido y fundamento del deber de motivación que hoy parece contraponerse veredicto inmotivado que admite el juicio por jurados.

\section{b. El autónomo de deber de motivación en la Corte Interamericana de Derechos Hu- manos y la Corte Suprema de la Nación y su caracterización como garantía del debido proceso}

Como hemos analizado con anterioridad (Villanueva, 2015, 2017), el primer precedente de la Corte Interamericana de Derechos Humanos que estableció claramente a la motivación como una garantía del debido proceso fue el caso "Yatama c/ Nicaragua" del año 2005. En este precedente se estableció entonces la falta de motivación como incumplimiento al derecho de la motivación que se encontraba reconocido implícitamente en el artículo 8.1. La CIDH en dicho caso consagra en el Sistema Interamericano de Derecho Humanos la fórmula por la cual estaría estableciendo un criterio amplio de justificación y que fija las bases de un deber autónomo de motivación, de un principio de justificación jurídica: Las decisiones que adopten los órganos internos que puedan afectar derechos humanos, tal como el derecho a la participación política, deben estar debidamente fundamentadas, pues de lo contrario serían decisiones arbitrarias.

En el texto reseñado afirmábamos que referido a la caracterización de la CIDH del concepto de motivación, en el caso "Chaparro Álvarez y Lapo Iñiguez" se la señala como "la exteriorización de la justificación razonada que permite llegar a una conclusión”. En el caso "Aspiz Barbera vs. Venezuela", donde por primera vez se va a analizar el incumplimiento por parte del estado de un deber autónomo de motivación, se recurre a la definición brindada en "Chaparro Álvarez" y finalmente es la que utiliza en el parágrafo 
254 de la propia Corte IDH, en el caso "V.R.P., V.P.C. y otros vs. Nicaragua". Cuando analizamos el alcance del deber de motivar vemos que la jurisprudencia de la Corte IDH anterior al fallo de referencia, sigue el principio de completitud de la motivación, el cual prescribe que la decisión jurisdiccional debe contener la justificación específica de todas las cuestiones de hecho y de derecho que constituyen el objeto de la controversia, dado que solo bajo esta condición, como afirma Taruffo (2008), se puede decir que la motivación es idónea para hacer posible el control sobre las razones que sustentan la validez y la aceptabilidad racional de la decisión. En la causa "Tristán Donoso vs. Panamá" se afirma que la sentencia debe incluir en la motivación las argumentaciones de las partes, de tal manera que la justificación del fallo debe mostrar que han sido analizados y valorados los alegatos de las partes y que el conjunto de pruebas. En la causa Chocrón Chocrón Vs. Venezuela" del año 2010, luego de reiterar la doctrina sentada en el caso "Tristán Donoso", se fijó el principio de completitud de la motivación al afirmar, las decisiones que adopten los órganos internos que puedan afectar derechos humanos deben estar debidamente fundamentadas, pues de lo contrario serían decisiones arbitrarias. En este sentido, la argumentación de un fallo y de ciertos actos administrativos debe permitir conocer cuáles fueron los hechos, motivos y normas en que se basó la autoridad para tomar su decisión, a fin de descartar cualquier indicio de arbitrariedad.

De esta manera, como hemos manifestado en otros trabajos sobre este tópico, la motivación queda calificada como deber y garantía, estableciendo una vinculación necesaria de la misma con la obligación de decidir conforme a derecho, a través de las razones que este suministra y la garantía correlativa de los ciudadanos de ser juzgados por estas, es decir, entre motivación y principio de legalidad, cual como hemos dicho anteriormente fue verdaderamente su origen histórico de la exigencia en nuestro sistema continental de derecho. En otro párrafo de este mismo fallo, la Corte afirma:

El Tribunal ha resaltado que las decisiones que adopten los órganos internos, que puedan afectar derechos humanos, deben estar debidamente fundamentadas, pues de lo contrario serían decisiones arbitrarias. En este sentido, la argumentación de un fallo debe mostrar que han sido debidamente tomados en cuenta los alegatos de las partes y que el conjunto de pruebas ha sido analizado. Asimismo, la motivación demuestra a las partes que éstas han sido oídas y, en aquellos casos en que las decisiones son recurribles, les proporciona la posibilidad de criticar la resolución y lograr un nuevo examen de la cuestión ante las instancias superiores. Por todo ello, el deber de motivación es una de las "debidas garantías" incluidas en el artículo 8.1 de la Convención para salvaguardar el derecho a un debido proceso.

La relevancia y claridad del texto es una prueba fundamental de la importancia y alcance dado al deber de motivación. La Corte, como hemos analizado, establece un criterio amplio respecto a los obligados y actos sobre los que recae, ya que deben ser motivadas todas las decisiones de los órganos internos, de cualquiera de los poderes del estado, que afecten los derechos humanos. Este parece una fuerte exigencia a los países miembros respecto a la forma de actuación de sus órganos internos. Entre ellas la Corte pone énfasis, en distintos fallos, en la función jurisdiccional, atenta su capacidad de afectar derechos como la libertad, la propiedad, el honor. Como puede observarse a través del fallo que venimos analizando, la Corte establece como fundamento de la motivación el derecho a ser oído, y el derecho al recurso y la exclusión de decisiones arbitrarias en un Estado de derecho. Esto tiene relevancia porque determina que la Corte IDH determina que el deber de motivar la resolución, tiene un fundamento más extenso que el derecho a recurso estableciendo de esta manera una obligación de motivar autónoma 
a este, que no se ve satisfecho ni aun estableciendo un sistema recursivo que satisfaga las condiciones de la Convención.

Por lo expuesto, la motivación requerida por la Corte Interamericana es la expresión completa de la justificación de la premisa fáctica y normativa, las razones que justifican la valoración de los elementos de prueba y la consideración de los argumentos de las partes. Esto no puede ser puede ser satisfecho en el sistema de juicio por jurado anglosajón con veredicto inmotivado y secreto donde no tenemos acceso a las razones que han tenido los juzgados legos para arribar a su decisión, su valoración de los elementos de prueba, ni la consideración de argumentos previos.

Lo cual como hemos señalado, luego del análisis conceptual realizado, es contradictorio con manifestar que en el juicio por jurados clásico existe motivación, ya que no existe la misma sin expresión de las razones que guiaron al juzgador a llevar a su conclusión, tanto lo referido a la identificación de la premisa normativa como el de la fijación de la premisa fáctica.

De la misma manera parece ser contradictorio con la idea de motivación que ha desarrollado la Corte Suprema y que ha quedado plasmada en el fallo "Casal" y en la teoría de la arbitrariedad.

La Corte Suprema de la Nación, intérprete último de la Constitución ha reconocido a la motivación de las resoluciones jurisdiccionales como una garantía constitucional dentro de nuestro Estado de Derecho. Una manifestación de este posicionamiento de la Corte, la encontramos en la doctrina de la Arbitrariedad. El primer precedente de esta doctrina la encontramos en el año 1909, en el caso Rey contra Rocha. En este caso el Tribunal sostuvo que "El requisito constitucional de que nadie puede ser privado de su propiedad sino en virtud de una sentencia fundada en ley, da lugar a recursos ante esta Corte en los casos extraordinarios de sentencias Arbitrarias, desprovistas de todo apoyo legal fundadas tan solo en la voluntad de los jueces."

A través de la doctrina de la Arbitrariedad, la CSJN amplía su competencia extraordinaria, con el fundamento último del principio de imperio de la ley del cual surgen las obligaciones de resolver la causa conforme a derecho y motivar la sentencia, a los fines de evitar la arbitrariedad entendida como la sustitución de la voluntad de ley por la voluntad del juez..$^{15}$

Que la Corte exige la motivación de la sentencia y no simplemente que se encuentre fundada en la ley, interpretando de esta manera el artículo 18 de la Constitución.

Genaro Carrió, en base a los fallos de la Corte, clasifica las siguientes causales de sentencia arbitraria, según su objeto o tema de decisión, a los fundamentos de la decisión y a los efectos de la decisión. (Carrio, 1983)

Con respecto a objeto de la decisión, una sentencia sería arbitraria según la Corte cuando omite considerar cuestiones propuestas oportunamente por las partes y cuando resuelve cuestiones no planteadas por estas. Estas causales que se vinculan con el principio de congruencia, claramente presuponen la expresión de la fundamentación en qué consiste la motivación. No se podría evaluar lo que ha sido considerado el tribunal sin su expresión.

Aún más clara es la procedencia de la misma, respecto a las causales que hacen a la fundamentación de la sentencia, en los casos en que:

15 Esto se evidenciarìa en los siguientes precedentes, entre otros: "La apreciación de la prueba constituye, como principio, facultad propia de los jueces de la causa y no es susceptible de revisión en la instancia extraordinaria, salvo en los casos en los que la sentencia revele arbitrariedad por no estar fundada o no constituye una derivación razonada del derecho vigente con aplicación a las circunstancias comprobadas de la causa." (CSJN, "Baiadera, Victor F" Fallos (1996) "Resulta arbitraria la sentencia si omitió considerar la prueba confesional del demandado sin brindar fundamentos que justifiquen su prescindencia y, por ende, ignorando sus efectos, no obstante ser reiteradamente invocada por la recurrente en sus agravios. Existió, pues una arbitraria omisión de analizar prueba decisiva" (C.S.J.N, "Cherhasso, Valdemar Peter y otro). 
-Se han apartado del fundamento normativo, que puede ocurrir cuando el juez desvincula su resolución de la legislación vigente en el momento de tomar la decisión, cuando se han apartado del texto legal sin dar razones de ello, cuando aplican normas derogadas o aun no vigentes o dan como fundamentos pautas de excesiva amplias, apartándose de la normativa aplicable.

-Respecto a la premisa fáctica, cuando se aparta de los hechos probados en la causa, al omitir la consideración de prueba decisiva, invocan la prueba inexistente o cuando contradicen abiertamente otras constancias de la causa.

-Respecto a ambas premisas y la vinculación con la conclusión cuando afirman premisas dogmáticas o infundadas, caen en exceso ritual o son autocontradictorias.

En todas estas causales de la sentencia arbitraria puede verse con claridad el presupuesto de la motivación de la sentencia, la sanción de arbitraria frente a la falta de motivación o motivación defectuosa, y la necesidad de motivación de la premisa normativa y la premisa fáctica. La doctrina de la arbitrariedad permite identificar la noción de fundamentación que sostiene la Corte y que coincide con la concepción anteriormente, como una operación lógica que se realiza a partir de una premisa normativa y una premisa fáctica, de la cual se deriva una conclusión normativa y en la que es necesaria la expresión de estos elementos y procesos a los fines evitar la arbitrariedad de la decisión.

\section{c. Contradicción entre su concepción respecto a la amplitud de los recursos y la acepta- ción de un veredicto inmotivado}

A pesar de que la Corte IDH afirma que el veredicto inmotivado del juicio por jurado clásico no afecta de por si las garantías de debido proceso, no trata en ningún momento del fallo la forma en que la inmotivación afectará el derecho al recurso de las partes, no analiza este punto tan transcendental y que es una de las principales objeciones que se le han hecho a esta clase de diseño.

La propia doctrina de la Corte IDH parece contrariar las limitaciones recursivas que plantea el veredicto inmotivado y la limitación que suele existir en esa clase de tradición respecto a la no recurribilidad del fallo absolutorio por parte de la parte acusadora y la victima constituida como querellante.

Hay una conexión entre la extensión de la obligación de motivación de sentencia y por otro lado, la extensión de la revisión en qué consiste el derecho al recurso. La Corte Interamericana sigue el principio de completitud de la motivación, el cual prescribe que la decisión jurisdiccional debe contener la justificación específica de todas las cuestiones de hecho y de derecho que constituyen el objeto de la controversia, dado que solo bajo esta condición se puede decir que la motivación es idónea para hacer posible el control sobre las razones que sustentan la validez y la aceptabilidad racional de la decisión (Taruffo, 2008). En la causa "Tristán Donoso vs. Panamá" se afirma que la sentencia debe incluir en la motivación las argumentaciones de las partes, de tal manera que la justificación del fallo debe mostrar que han sido analizados y valorados los alegatos de las partes y que el conjunto de pruebas. ${ }^{16}$ En la causa "Chocrón Chocrón Vs. Venezuela" del año 2010, luego de reiterar la doctrina sentada en el caso "Tristán Donoso", se fijó el principio de completitud de la motivación al afirmar. En este sentido, la argumentación de un fallo y de ciertos actos administrativos debe permitir conocer cuáles fueron los hechos, motivos y normas en que se basó la autoridad para tomar su decisión, a fin de descartar cualquier indicio de arbitrariedad..$^{18}$ Por lo expuesto y como ya manifestamos,

\footnotetext{
16 ECorte IDH, CASO “TRISTÁN DONOSO VS. PANAMA”- Sentencia 27/01/09, Considerando 153.

17 Corte IDH, CASO “CHOCRON CHOCRON VS. VENEZUELA” - Sentencia 01/07/11.

18 22Corte IDH, CASO "CHOCRON CHOCRON VS. VENEZUELA" - Sentencia 01/07/11, C. 118
} 
la motivación requerida por la Corte Interamericana es la expresión completa de la justificación de la premisa fáctica y normativa, las razones que justifican la valoración de los elementos de prueba y la consideración de los argumentos de las partes.

Correlativa a esta noción de motivación completa de la sentencia se encuentra el derecho a recurrir la sentencia, de tal manera que se garantice un examen integral de la decisión recurrida. el ejercicio del derecho procesal básico de revisión de una decisión adversa por parte de un órgano jurisdiccional (doble instancia) es un derecho fundamental reconocido por el Pacto Internacional de Derechos Civiles y Políticos y en la Convención Americana de Derechos Humanos, también conocido como Pacto de San José de Costa Rica. Estas disposiciones contenidas en los Tratados Internacionales de Derechos Humanos que a partir de la última reforma constitucional gozan explícitamente de jerarquía constitucional (art. 75 inciso 22) integrando en consecuencia el "bloque de constitucionalidad". Son normas supremas internacionales ratificadas por el Estado y expresamente incorporadas, a partir de la reforma del año 1994, a nuestro supremo ordenamiento jurídico. El derecho al recurso de la sentencia definitiva es para el imputado una garantía constitucional expresa y autónoma y también hay elementos para afirmar que lo mismo se encuentra reconocido a la víctima de un delito.

La Convención Americana sobre Derechos Humanos establece en su artículo 8 (garantías judiciales), que toda persona tiene "... h) derecho de recurrir del fallo ante juez o tribunal superior." (art. 8.2.h). Esta garantía fundamental que se ubica en la cúspide del ordenamiento jurídico subordina de pleno imperio cualquier disposición "infra" constitucional que se contraponga, que limite o directamente viole dicho derecho, pues el principio de supremacía constitucional supone (e impone) adecuación de los derechos (y más aún la reglamentación de los derechos y las normas procesales) al texto y espíritu constitucional. Si una norma infra constitucional contraviene dicho principio, la norma en pugna debe ser declarada inconstitucional por los órganos jurisdiccionales.

Así la Corte Interamericana de Derechos Humanos en el caso "HERRERA ULLOA 19" sentó un precedente importante al sostener que de acuerdo al objeto y fin de la Convención Americana, cual es la eficaz protección de los derechos humanos, se debe entender que el recurso que contempla el artículo 8.2.h. de dicho tratado debe ser un recurso ordinario eficaz mediante el cual un juez o tribunal superior procure la corrección de decisiones jurisdiccionales contrarias al derecho. Si bien los Estados tienen un margen de apreciación para regular el ejercicio de ese recurso, no pueden establecer restricciones o requisitos que infrinjan la esencia misma del derecho de recurrir del fallo ${ }^{20}$. Respecto a la extensión de este derecho, la Corte en este fallo afirma: "Independientemente de la denominación que se le dé al recurso existente para recurrir un fallo, lo importante es que dicho recurso garantice un examen integral de la decisión recurrida. ${ }^{21}$

Con respecto a la Corte Suprema de la Nación también se da una contradicción similar. A pesar de que explícitamente en el fallo "Canales" afirma que el juicio por jurados clásicos no viola garantías de debido proceso porque no afecta el derecho al recurso, esto es un erróneo en más de un sentido, es una afirmación dogmática pues no analiza el sistema de recursos del modelo de juicio por jurados clásico y lo compara con sus propias exigencias y criterios sobre el derecho al recurso y es una autocontradictoria con la forma de entender la amplitud del derecho al recurso.

Esta exigencia de motivación integral y el derecho a recurso, también ha sido recono-

19 Corte IDH, "HERRERA ULLOA VS. COSTA RICA” - Sentencia 02/07/2004.

20 Corte IDH, "HERRERA ULLOA VS. COSTA RICA” - Sent 02/07/2004, Considerando 161.

21 Corte IDH, "HERRERA ULLOA VS. COSTA RICA" - Sent 02/07/2004, Considerando 165. 
cida explícitamente por el fallo "Casal22" de la CSJN. Este importante precedente, que en su fundamentación analiza cuestiones relevantes como son las garantías del debido proceso, la defensa en juicio, el derecho al recurso y sus alcances como así también consideraciones relevantes respecto a la sana critica racional, juez natural y el juicio por jurado, abriendo un conjunto de expectativas respecto a las transformaciones pretorianas que establecía el precedente (Grisetti, 2005).Entre sus temas centrales el fallo Casal introduce la idea de la necesidad de la ampliación de la revisión en casación a los fines de asegurar el derecho al doble conforme de la cuestión fáctica. La exigencia se encuentra fundada en el artículo 8.2 de la Convención Americana de Derechos Humanos (Pacto de San José de Costa Rica).

Hasta el momento de la resolución, la casación vedaba la reconsideración de las cuestiones fácticas, sin embargo, a partir del caso "Casal", la Corte se inclina por la idea de una revisión amplia, de un recurso amplio, que significa que debe ser revisable todo lo posible. Al desarrollar su tesis, la Corte preconiza lo que ella misma denomina (con cita de la doctrina alemana) como "teoría del agotamiento de la capacidad de revisión o de la capacidad de rendimiento (Leistungsfähigkeit)"30, conforme a la cual, el Tribunal de Casación debe extender su competencia correctiva a todos los aspectos del fallo que sean materia de embate, con la sola limitación de aquellas cuestiones que sea imposible controlar, como secuela de la oralidad. (Grisetti, 2005)

De esta manera preciso realizar la discusión respecto al juicio por jurados, ya que, en el modelo anglosajón tomado como inspiración por el constituyente originario, la consideración de la premisa fáctica resuelta en el veredicto del jurado, era arribada a través del sistema de intima convicción. Lo cual, en principio, no permitiría la revisión de la sentencia sobre este aspecto. Así en el fallo "Casal" se estableció la Corte:

La doctrina en general rechaza en la actualidad la pretensión de que pueda ser válida ante el derecho internacional de los Derechos Humanos una sentencia que se funde en la llamada libre o íntima convicción, en la medida en que por tal se entienda un juicio subjetivo de valor que no se fundamente racionalmente y respecto del cual no se pueda seguir (y consiguientemente criticar) el curso de razonamiento que lleva a la conclusión de que un hecho se ha producido o no o se ha desarrollado de una u otra manera. Por consiguiente, se exige como requisito de la racionalidad de la sentencia, para que ésta se halle fundada, que sea reconocible el razonamiento del juez. Por ello se le impone que proceda conforme a la sana crítica, que no es más que la aplicación de un método racional en la reconstrucción de un hecho pasado.

Que, conforme a lo señalado, la regla de la sana crítica se viola cuando directamente el juez no la aplica en la fundamentación de la sentencia. Puede decirse que, en este caso, la sentencia carece de fundamento y, por ende, esta es una grosera violación a la regla que debe ser valorada indefectiblemente tanto por el tribunal de casación como por esta Corte. Cuando no puede reconocerse en la sentencia la aplicación del método histórico en la forma en que lo condicionan la Constitución y la ley procesal, corresponde entender que la sentencia no tiene fundamento. En el fondo, hay un acto arbitrario de poder. La consecuencia de este obiter dicta de la Corte Suprema de Justicia de la Nación es la incompatibilidad de la Institución de los Jurados siempre que este se encuentre diseñado con un sistema de valoración de la prueba de íntima convicción, como es el sistema anglosajón puro, con veredicto inmotivado y secreto. 


\section{Conclusión}

La exigencia de fundar legal y lógicamente la sentencia no puede ser entendida de otra manera, desde una interpretación conforme, como exigencia de expresión de las razones que fundamentan la sentencia, esto es como motivación de las mismas. Del análisis de la jurisprudencia de la Corte Interamericana, surge que existe obligación de motivar la decisión jurisdiccional en nuestro bloque constitucional que deriva de la Convención Americana de Derechos Humanos. Que la misma obligación recae sobre el tribunal que toma una decisión que pueda afectar derechos humanos, sin distinción entre el carácter técnico o lego del mismo. Que la motivación es una garantía autónoma dentro de las garantías del debido proceso, que se encuentra vinculado a la interdicción de la arbitrariedad, al control del derecho a ser oído y al derecho al recurso. Hemos analizado como la instauración del diseño de juicio por jurado de diseño clásico, vulnera estas garantías procesales del debido proceso, mostrando como resulta auto contradictoria la manera en que la Corte Interamericana y la Corte Suprema comprenden la motivación y la amplitud al derecho al recurso.

Nosotros participamos de la idea de que el juicio por jurado es una garantía de la imputados, pero, sobre todo, vinculado con el ideal de autogobierno ciudadano, de un derecho de los miembros de la comunidad política a participar de una tarea esencial como es la administración de justicia.

Sin embargo, para resolver esta tensión basta con la aplicación del principio de proporcionalidad, para comprobar que se presenta como una falsa alternativa optar por renunciar a cierta clase de derechos en función del conflicto que prima facie existiría. ¿Consideramos que el modelo de juicio por jurados clásico no pasa el filtro del principio de necesidad del principio más amplio de proporcionalidad? La existencia de otros diseños de jurados, que permiten el no sacrificio de los derechos en juego, como es el diseño escabinado o el mixto o ensamblado establecido en la provincia de Córdoba, es suficiente para mostrar que hay medidas de diseño institucional de la participación ciudadana menos gravosas. Esperemos que los legisladores provinciales y nacionales continúen en la dirección de la reforma procesal penal incorporando a la ciudadanía a la tarea de juzgar, que como decía Toqueville, es una escuela de la democracia, pero eligiendo otros diseños institucionales que no vulneren derechos de los imputados, la víctima y la ciudadanía.

\section{BIBLIOGRAFÍA}

- Alchourron, C., \& Bulygin, E. (1975). Introducción a la metodología de las ciencias jurídicas y sociales. Buenos Aires: Astrea.

- Atienza, M. (2005). Las razones del derecho. México : Universidad Autonoma de México.

- Bayon Mohino, J. C. (1996). Principios y reglas: legislación y jurisdicción en el Estado Constitucional. Jueves para la democracia, 41-49.

- Bulygin, E. (1991). Sentencia judicial y creación del derecho. Madrid: Centro de Estudios Constitucionales.

- Forst, R. (2005). El derecho Básico a la justificación: Hacia una concepción constructivista de los derechos humanos. Estudios Politicos. 
- Gascon Abellan, M. (1998). El imperio de la ley. Motivos para el desencanto. Jueces para la democracia, 25-35.

- Griseti, R. A. (2005). Algunos interrogantes que plantea el caso Casal. [Versión electrónica], La Ley Online.

- Harfuch. (2012). Inmotivacion, secreto y recurso amplio en el juicio por jurados. Revista Derecho Penal.

- Hart, H. (1995). El concepto de derecho. Buenos Aires: Abeledo Perrot.

- Ibañez, P. (1992). Acerca de la motivación de Iso hechos en la sentencia penal. Doxa.

- Laporta, F. (1994). Imperio de la ley. Doxa, 133-145.

- Maier, J. (1989). Derecho procesal penal Argentino. Buenos Aires : Hammurabi.

- Nino, C. S. (1992). Fundamentos de Derecho Constitucional. Buenos Aires: Astrea.

- Pastor, D. (2010). El deber judicial de motivar las condenaciones. Reflexiones sobre el procedimiento penal. Buenos Aires: Ad-Hoc.

- Seña, M. (2008). El error judicial y la formación de los jueces. Barcelona: Gedisa.

- Pastor, D. (2010). El deber judicial de motivar las condenaciones. En D. y. Pastor, Reflexiones sobre el procedimiento penal. Buenos Aires: Ad-Hoc.

- Villanueva, C (2015) Obligación de motivar las decisiones judiciales a la luz de las resoluciones de la Corte Interamericana de Derechos Humanos: Su implicancia respecto a la convencionalidad de la incorporación juicio por jurado anglosajón con veredicto secreto e inmotivado. Publicada en la página XXVIII Congreso Nacional de Derecho Procesal, sitio https://www.procesal2015.org.ar/images/Ponencia_Carlos_VillanuevaComisi\%C3\%B3n_2._Tema_juicio_por_jurado.pdf

- Villanueva, C. (2017a). Hacia un fundamentación constructivista del principio de justificación judicial: la reconstrucción de una vía dialógica a partir de la teoría de fundamentación de derechos humano de Rainer Forst. En R. Sanchez Brigido, C. Longhini, C. M. Villanueva, \& D. Domeniconi, Constructivismo y Derechos Fundamentales (pág. 192). Córdoba: Lex.

- Villanueva, C. M. (2017). El deber de motivar legal y logicamente las sentencias del artículo 155 de la Constitución Provinicial como garantia de debido proceso y su implicancia en el diseño de participación ciudadana en la justicia penal. En J. E. (Compilador), Treinta años de la Reforma Constitucional (pág. 349). Córdoba: Editorial UNC. 